\title{
Detection of Fimbriae and Fimbrial Antigens on the Oral Anaerobe Bacteroides gingivalis by Negative Staining and Serological Methods
}

\author{
By YUMIKO SUZUKI, ${ }^{1}$ FUMINOBU YOSHIMURA, ${ }^{2 *}$ \\ KOUI TAKAHASHI, ${ }^{3}$ HIROSHI TANI ${ }^{1}$ AND TAKESHI SUZUKI ${ }^{2}$ \\ Departments of ${ }^{1}$ Preventive Dentistry and ${ }^{2}$ Microbiology, School of Dentistry, and ${ }^{3}$ Department \\ of Animal Science, Faculty of Agriculture, Hokkaido University, Sapporo 060, Japan
}

(Received 9 May 1988)

\begin{abstract}
We screened 63 clinical isolates of Bacteroides gingivalis from eight different laboratories for the presence of fimbriae by negative staining and by immunological methods. Techniques used were bacterial agglutination, Ouchterlony immunodiffusion and Western immunoblotting analysis using rabbit anti-fimbriae and anti-fimbrilin sera raised against fimbriae and fimbrilin (a constituent protein of $B$. gingivalis fimbriae) from $B$. gingivalis strain 381 . In 49 of the 51 strains tested, fimbriae were clearly detected by negative staining, and $30(60 \%)$ of the fimbriate strains were positive in all three of the immunological assays. A total of 37 strains $(75 \%)$ were positive by immunoblotting analysis, which was the most reliable of the serological methods used in this study. The study shows that the majority of $B$. gingivalis strains are fimbriate, and that these fimbriae are immunologically related to the fimbriae of $B$. gingivalis strain 381 . Molecular heterogeneity of fimbrilin was discovered by the immunoblotting analysis, when different strains were compared. With most of the strains, including strain 381 , the antifimbrilin serum reacted with a protein of apparent molecular mass $43 \mathrm{kDa}$, but with 15 strains the immuno-reactive protein had an apparent molecular mass of $46 \mathrm{kDa}$.
\end{abstract}

\section{INTRODUCTION}

Bacteroides gingivalis, a Gram-negative oral anaerobe, is a suspected periodontal pathogen (Slots \& Genco, 1984) and it has been suggested that to facilitate colonization in periodontal pockets, $B$. gingivalis has several surface components which function as adherence factors (Holt, 1982).

Fimbriae, which are filamentous, proteinaceous appendages, seem to be one of the specific surface components responsible for adherence in this organism (Okuda \& Takazoe, 1974; Slots \& Gibbons, 1978; Okuda et al., 1981). Recently, B. gingivalis fimbriae have been purified to homogeneity from strain 381 , and their chemical, morphological and immunological properties have been characterized (Yoshimura et al., 1984b, 1985). In addition, purified fimbriae and antibodies against them have been obtained in sufficient quantities for clinical applications such as immunodiagnosis. For their successful clinical application, several other characteristics of fimbriae have to be elucidated; for example, their prevalence among $B$. gingivalis clinical isolates and the precise function of fimbriae as an adherence factor.

A recent morphological study (Handley \& Tipler, 1986) and our previous report (Yoshimura et $a l ., 1984 b)$ have shown that $B$. gingivalis fimbriae are thin, curly filaments (4-5 $\mathrm{nm}$ in width, with a pitch of about $34 \mathrm{~nm}$ ). The thin nature of fimbriae may explain why these structures have not been previously revealed in detail. It was also shown that $B$. gingivalis fimbriae were not responsible for haemagglutination (Yoshimura et al., 1984b) and therefore screening for fimbriation by haemagglutination was not possible. We have previously shown the presence of fimbriae in B. gingivalis ATCC 33277, the type strain (Yoshimura et al., 1984b). However, only two B. gingivalis strains (381 and ATCC 33277) and a few related Bacteroides were examined 
because the primary purpose of the study was to characterize the properties of fimbriae from strain 381. Therefore, a more comprehensive survey of $B$. gingivalis strains from various laboratories was necessary, particularly since various strains have been used for the measurement of humoral response to the organism without any consideration of the presence of fimbriae (Tew et al., 1985). This study presents such a survey.

\section{METHODS}

Bacterial strains and growth conditions. The 63 strains of B. gingivalis used were isolated from the human oral cavity except for strains 222 and Shirai, which were from ear pus and abdominal ascites, respectively. The 51 strains that were tested by all four methods, and their sources, are listed in Table 1. Other strains used were $B$. asaccharolyticus ATCC 25260, B. melaninogenicus ATCC 25845, B. loescheii ATCC 15930, B. denticola ATCC 33185, B. intermedius ATCC 25611, B. levii B-151, B. endodontalis ATCC 35406 and B. macacae ATCC 33141. All bacteria were grown anaerobically at $37^{\circ} \mathrm{C}$ in a general anaerobic medium (GAM), either in broth or in semi-solid medium (Nissui, Tokyo, Japan) and Brucella laked HK blood agar (Kyokuto, Tokyo, Japan) as described previously (Yoshimura et al., 1984a).

The strains of $B$. gingivalis received were tested in an API ZYM (Analytab Products, Plainview, NY, USA) system to verify their identification as $B$. gingivalis strains.

Preparation of fimbriae, cell lysates and antisera. B. gingivalis fimbriae from strains 381 and ATCC 33277 were purified essentially as described previously (Yoshimura et al., 1984b). B. gingivalis cells, gently washed once, were

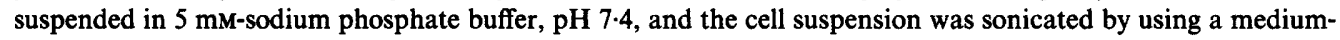
sized Tomy Seiko UR 200P sonicator probe with ten $1 \mathrm{~min}$ bursts at $0^{\circ} \mathrm{C}$. Cell lysates were obtained as a supernatant after unbroken cells were removed by centrifugation at $1000 \mathrm{~g}$ for $10 \mathrm{~min}$. Antisera against $B$. gingivalis fimbriae (strain 381) and their denatured fimbrilin monomers were prepared as described previously (Yoshimura et al., 1984b).

Bacterial agglutination. Bacteria were grown anaerobically for $24-40 \mathrm{~h}$ (to late exponential phase) and collected by centrifugation at $1500 \mathrm{~g}$ for $20 \mathrm{~min}$. The cells were suspended to an $\mathrm{OD}_{600}$ of 1.0 in buffer $\mathrm{A}(20 \mathrm{mM}-\mathrm{Tris} / \mathrm{HCl}$, pH 8.0, with $0.15 \mathrm{M}-\mathrm{NaCl}$ and $10 \mathrm{mM}-\mathrm{MgCl}_{2}$ ) without washing. The sera were first diluted with buffer $A$ in twofold serial steps either on a haemagglutination plate (each well, $0.5 \mathrm{ml}$ ) or on a microplate (each well, $0.06 \mathrm{ml}$ ). The cell suspensions $(0.5$ and $0.06 \mathrm{ml}$, respectively) were added to and mixed with diluted antisera in the wells. The plate was then incubated for $1.5 \mathrm{~h}$ at room temperature. Two controls were run for each test: B. gingivalis 381 (strong positive, parent strain) with anti-fimbriae serum, and strains to be tested with pre-immune serum for autoagglutination.

Ouchterlony immunodiffusion. The agar contained $1 \%(\mathrm{w} / \mathrm{v})$ agarose, $0.85 \% \mathrm{NaCl}, 1 \%(\mathrm{v} / \mathrm{v})$ Triton $\mathrm{X}-100,0 \cdot 1 \%$ SDS and $0.02 \% \mathrm{NaN}_{3}$. The agar was boiled, cooled to $50{ }^{\circ} \mathrm{C}$, and poured into Petri dishes. A dense bacterial cell suspension (adjusted to $10 \mathrm{OD}_{600}$ units from more dense cell suspensions whose $\mathrm{OD}_{600}$ were determined by diluting 100 -fold and by measuring $\mathrm{OD}_{600}$ values ranging from $0 \cdot 1$ to 0.8 ) was prepared for the quantitative assay as described above, mixed with SDS $\left(10 \%\right.$, w/v) to give a final concentration of $0.5 \% \mathrm{SDS}$, and heated at $100{ }^{\circ} \mathrm{C}$ for $5 \mathrm{~min}$. The heated and denatured cell suspension, and anti-fimbrilin serum without dilution, were placed into wells $(15 \mu \mathrm{l})$ in the agarose plates. A denatured cell suspension of $B$. gingivalis 381 was always run as a positive control.

SDS-PAGE and Western blotting analysis. SDS-PAGE was done in a $1.0 \mathrm{~mm}$ thick slab gel $(12 \%, \mathrm{w} / \mathrm{v})$ as described by Lugtenberg et al. (1975). The cell lysates were heated with SDS at $100^{\circ} \mathrm{C}$ for $5 \mathrm{~min}$. Electrophoretic transfer of proteins in gels to nitrocellulose sheets was done with a Trans-Blot apparatus with a cooling coil as described by Towbin et al. (1979) (Western blotting). The transfer was done at $6 \mathrm{~V} \mathrm{~cm}^{-1}$ overnight while being cooled with tap water. The transferred nitrocellulose sheet was treated with buffer B $(20 \mathrm{mM}$-Tris/ $/ \mathrm{HCl}, \mathrm{pH} 7 \cdot 4$, with $0.5 \mathrm{M}-\mathrm{NaCl}$ ) containing $1 \%(\mathrm{w} / \mathrm{v})$ bovine serum albumin (BSA) to block unoccupied protein-binding sites. The blocked sheet was incubated with buffer B $(20-30 \mathrm{ml})$ containing BSA and anti-fimbrilin serum (usually 1000fold dilution) for $4 \mathrm{~h}$ or more, followed by three successive washings with buffer B containing $0.05 \%$ Tween 20 . The sheet was then incubated with buffer B containing BSA and horseradish-peroxidase-conjugated IgG fraction goat anti-rabbit IgG (F[ab'] $]_{2}$ specific, Cappel Lab 2000-fold dilution) for $4 \mathrm{~h}$ or more, followed by the same washings. For detection of immuno-reactive proteins, the sheet was soaked in a solution composed of $5 \mathrm{ml}$ 4chloro-1-naphthol ( $3 \mathrm{mg} \mathrm{ml}^{-1}$ in methanol) and $25 \mathrm{ml}$ buffer $\mathrm{B}$ containing $15 \mu \mathrm{H}_{2} \mathrm{O}_{2}$. The incubation was done for 15-30 min, and the reaction was stopped by washing with distilled water. All immuno-assays were done twice or more.

Electron microscopy. Cells in the late exponential phase (from a $24-48 \mathrm{~h}$ culture) were collected by centrifugation ( 2000 r.p.m. for $20 \mathrm{~min}$ ) from a $10 \mathrm{ml}$ culture, suspended in $20 \mathrm{mM}$-Tris/HCl, $\mathrm{pH} 7 \cdot 4$, with $0.15 \mathrm{M}-\mathrm{NaCl}$ and $10 \mathrm{mM}$ $\mathrm{MgCl}_{2}$ and negatively stained with $1 \%$ (w/v) phosphotungstic acid ( $\left.\mathrm{pH} 7 \cdot 4\right)$. Copper grids (150 mesh) were covered with a thin film of collodion, which was then coated with carbon. The supported films were made 
hydrophilic by ion bombardment before use. A drop of cell suspension ( $0.2 \mathrm{OD}_{600}$ units) were applied to the specimen grid, which was then rinsed with $0 \cdot 1 \mathrm{M}-\mathrm{NaCl}$ several times, and the solvent was repeatedly replaced by $1 \%$ phosphotungstic acid.

Analytical methods. The amount of protein in cell lysates and in fimbrial preparations was determined by Lowry's method, with BSA as the standard, and standard amounts of protein were run on the gels.

\section{RESULTS}

Morphological screening. Of 63 strains tested, 49 were clearly seen to be fimbriate by electron microscopy, and curly fimbriae similar to those on 381 could be seen after negative staining with phosphotungstic acid. We were unable to determine whether the remaining 14 strains had fimbriae, primarily as a result of unsatisfactory sample preparation for the electron microscope in spite of several trials. Typical whole cells of fimbriate and non-fimbriate strains are shown in Fig. 1. Strain 14018 had many short fimbriae (Fig. 1a), and D43B-4 had fewer fimbriae on the cells (Fig. 1b). D40C-28 was non-fimbriate (Fig. 1c), and a few detached fimbriae were observed in the case of W83 (data not shown).

Bacterial agglutination with anti-fimbriae serum. The rabbit anti-serum against fimbriae from strain 381 clearly and strongly agglutinated cells of homologous strain 381 , as well as those of the type strain ATCC 33277, with a comparable titre of 6400 to 12800 (Yoshimura et al., 1984b,
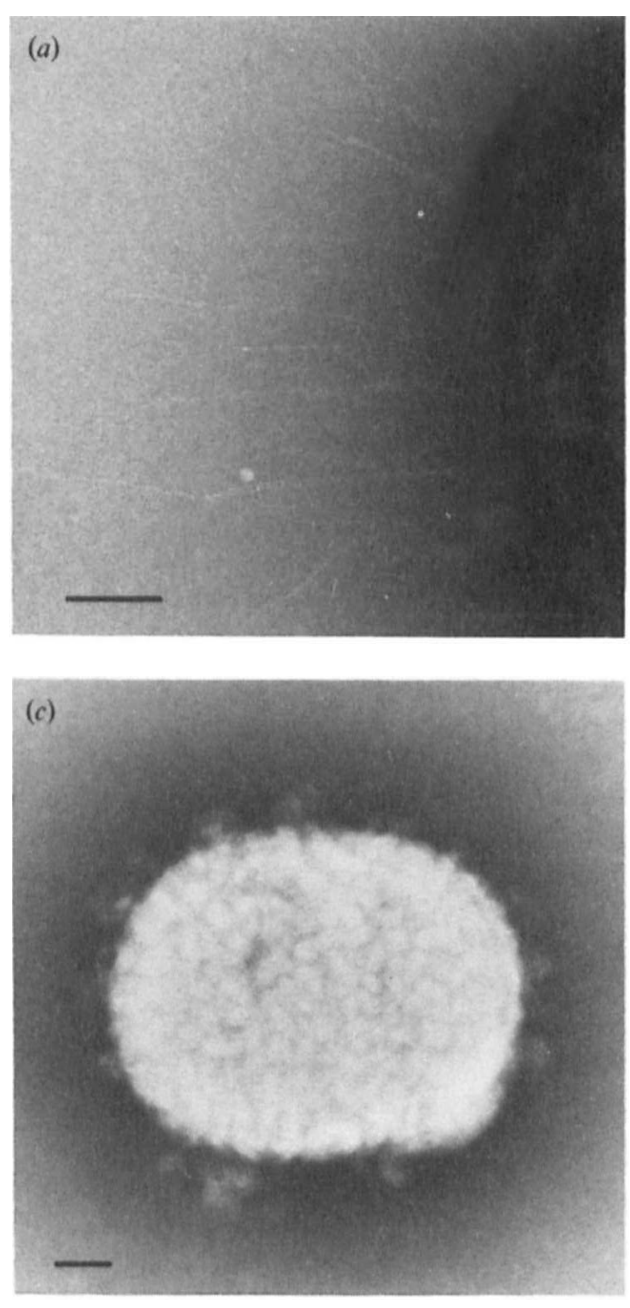

(b)

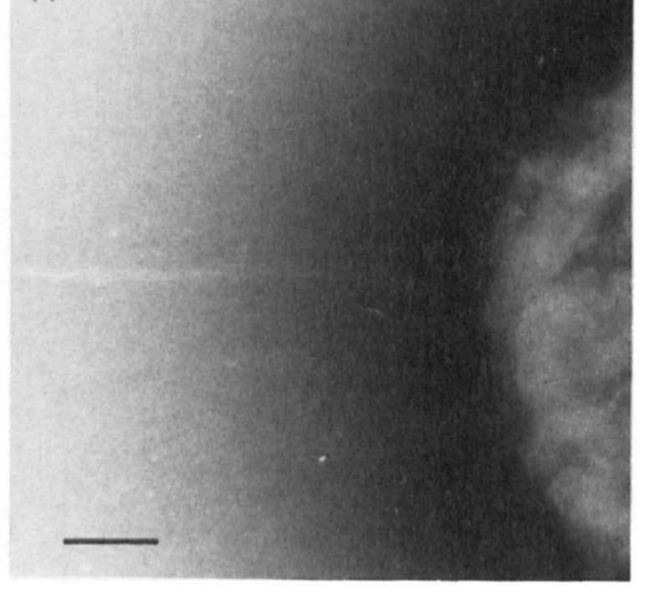

Fig. 1. Electron micrographs of a whole cell of $B$. gingivalis. The cells were negatively stained with $1 \%$ phosphotungstic acid. (a), 14018, many short fimbriae; (b), D43B-4, fewer fimbriae; (c), D40C28 , nonfimbriate. Bar, $0.1 \mu \mathrm{m}$. 
Table 1. Screening of B. gingivalis clinical isolates for fimbriae

The data show positive $(+)$ or negative $(-)$ results for each assay. Bacterial agglutination rated from negative $(-)$ to a + (titre of $<64), 2+$ (titres of 128-800) and $3+$ (titres of $>1600$ ). The presence of fimbriae under electron microscopy rated from negative $(-)$ to positive $(+$, some; $2+$, many). Fimbriae from strain 381 are called 381 fimbriae.

\begin{tabular}{|c|c|c|c|c|c|}
\hline Strain & Source* & $\begin{array}{c}\text { Bacterial } \\
\text { agglutination } \dagger\end{array}$ & $\begin{array}{l}\text { Ouchterlony } \\
\text { immunodiffusion }\end{array}$ & $\begin{array}{l}\text { Western } \\
\text { blotting }\end{array}$ & $\begin{array}{l}\text { Electron } \\
\text { microscopy }\end{array}$ \\
\hline
\end{tabular}

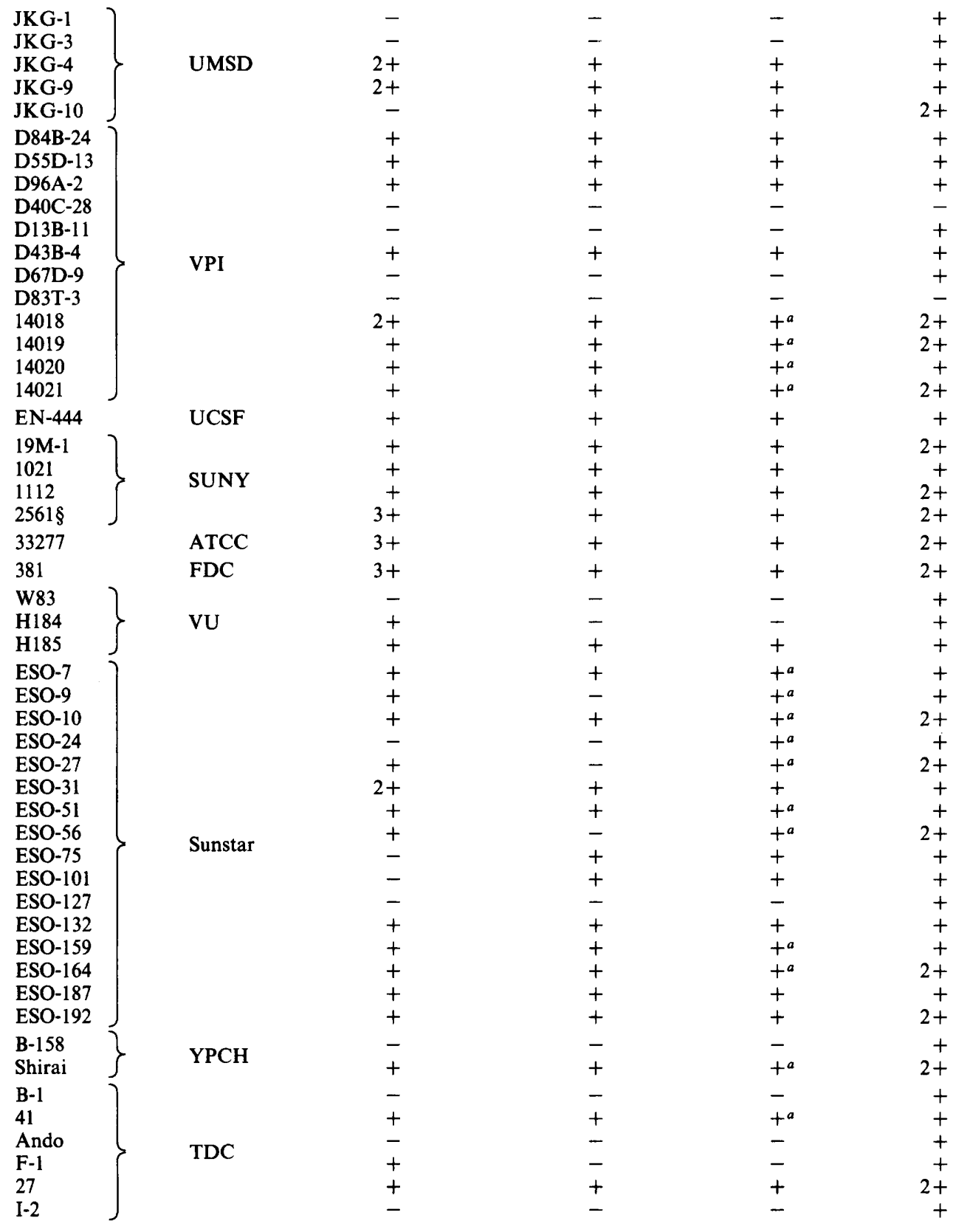

* UMSD, University of Michigan, School of Dentistry, USA; VPI, Virginia Polytechnic Institute, USA; UCSF, University of California, San Francisco, USA; SUNY, State University of New York at Buffalo, USA; FDC, Forsyth Dental Center, USA; VU. Vrije Universiteit, The Netherlands; Sunstar, Sunstar Inc., Osaka, Japan; YPCH, Yamaguchi Prefectural Central Hospital, Japan; TDC, Tokyo Dental College, Japan. $\dagger$ Using anti-381 fimbriae serum.

$\ddagger$ Using anti-381 fimbrilin serum. $a$ indicates the presence of the $46 \mathrm{kDa}$ protein instead of the $43 \mathrm{kDa}$ protein, fimbrilin, of strain 381 .

$\S$ An original strain of ATCC 33277. 

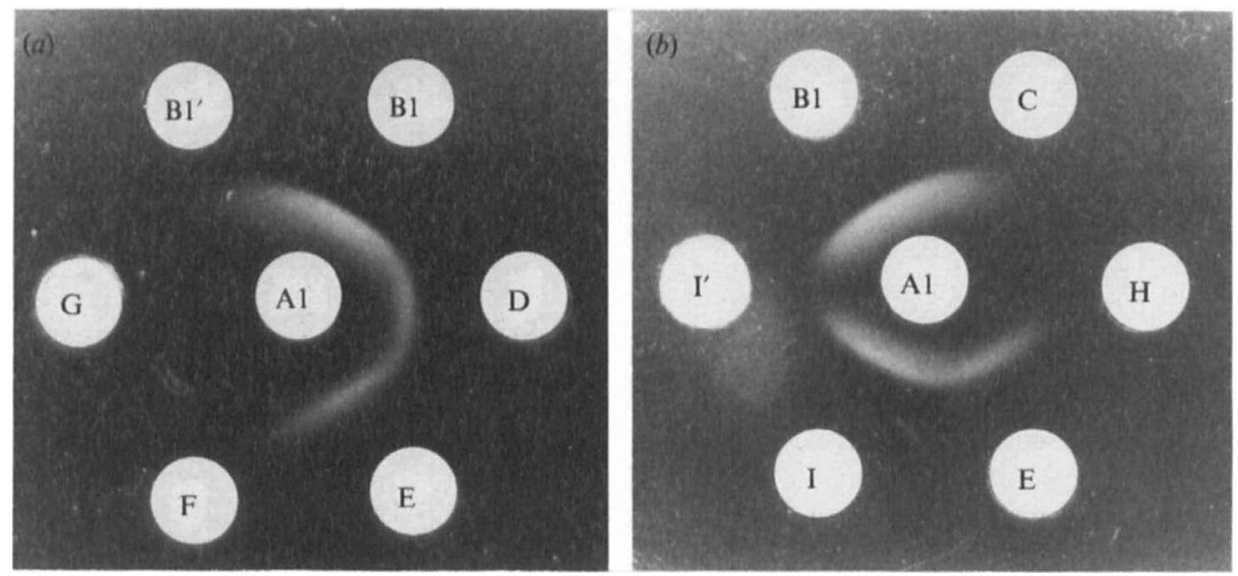

Fig. 2. Ouchterlony immunodiffusion anlaysis with rabbit anti-fimbrilin serum. Bacterial cell suspensions, used as the antigens, were adjusted to a high cell density. Antigens which were unheated (marked ') or heated at $100^{\circ} \mathrm{C}$ for $5 \mathrm{~min}$ in SDS, and the antisera, were placed into wells (about $15 \mu \mathrm{l}$ ) in an agarose plate containing detergents. $\mathrm{A} 1$, rabbit anti-381 fimbrilin serum; $\mathbf{B} 1$, and $\mathbf{B 1}^{\prime}$, purified fimbriae from strain $381 ; \mathrm{C}$, partially purified $75 \mathrm{kDa}$ protein, a major protein in B. gingivalis ; D, $B$. gingivalis 381 ; E, B. gingivalis ATCC 33277; F, B. macacae ATCC 33141 ; G, B. intermedius ATCC $25611 ; \mathrm{H}, B$. asaccharolyticus ATCC 25260 ; I, and $\mathrm{I}^{\prime}$, a soluble fraction, after ultracentrifugation, of $B$. gingivalis 381 (see Yoshimura et al., 1984b for the $75 \mathrm{kDa}$ protein).

Table 1). Of 62 strains tested, 37 were positive. (Only the strains examined by all tests are listed in Table $1 ; 35$ of these were positive in the agglutination assay.) In contrast with strains 381 and ATCC 33277 (2561, the original strain), many of the positive strains showed only low titres (less than 64). This could be due to fewer numbers of fimbriate cells in a population, less fimbriation on cell surfaces, or the presence of immunologically different fimbriae. Other methods, such as Ouchterlony immunodiffusion and Western blotting using a rabbit anti-fimbrilin serum, were applied to confirm the results of bacterial agglutination. The anti-fimbrilin serum had a different specificity from the anti-fimbriae serum which was used for the agglutination test (Yoshimura et al., 1984b, 1985).

Ouchterlony immunodiffusion analysis with anti-fimbrilin serum. Since the anti-fimbrilin serum was monospecific to SDS-denatured fimbrilin monomers, dense cell suspensions were heated in SDS (final concentration $0.5 \%$ ) at $100^{\circ} \mathrm{C}$. The heated cell suspensions were placed in wells on an agarose plate containing detergents to detect whether they produced a precipitation line with the original anti-fimbrilin serum and whether the line fused with the one from the cell suspension of strain 381 used as a positive control. Typical results are shown in Fig. 2 (the precipitation lines are not very sharp because of the presence of detergents). Of 62 strains tested with the positive control, 36 were positive. In some strains, the results from bacterial agglutination and Ouchterlony tests were contradictory (Table 1). This could be due to the anti-fimbriae and the anti-fimbrilin sera having different specificities, presumably recognizing surface epitopes on native fimbriae and more conservative, inner regions of fimbriae, respectively. Alternatively, the contradictory results may simply be due to differences in the detection limits of the assays. Since anti-fimbrilin serum was raised by injecting rabbits with purified fimbrilin taken from stained SDS-PAGE gels, it was comparatively more specific than the anti-fimbriae serum, which was prepared by injecting rabbits with the fimbrial preparation before gel electrophoresis. In fact, only a single precipitation line was ever observed in Ouchterlony immunodiffusion plates under conditions where a high cell density and the original antifimbrilin serum were used. In order to confirm that the precipitation line was really caused by fimbrilin protein, a third method was sought to detect the fimbrilin band at a corresponding migration rate by using an immunoblotting technique. 


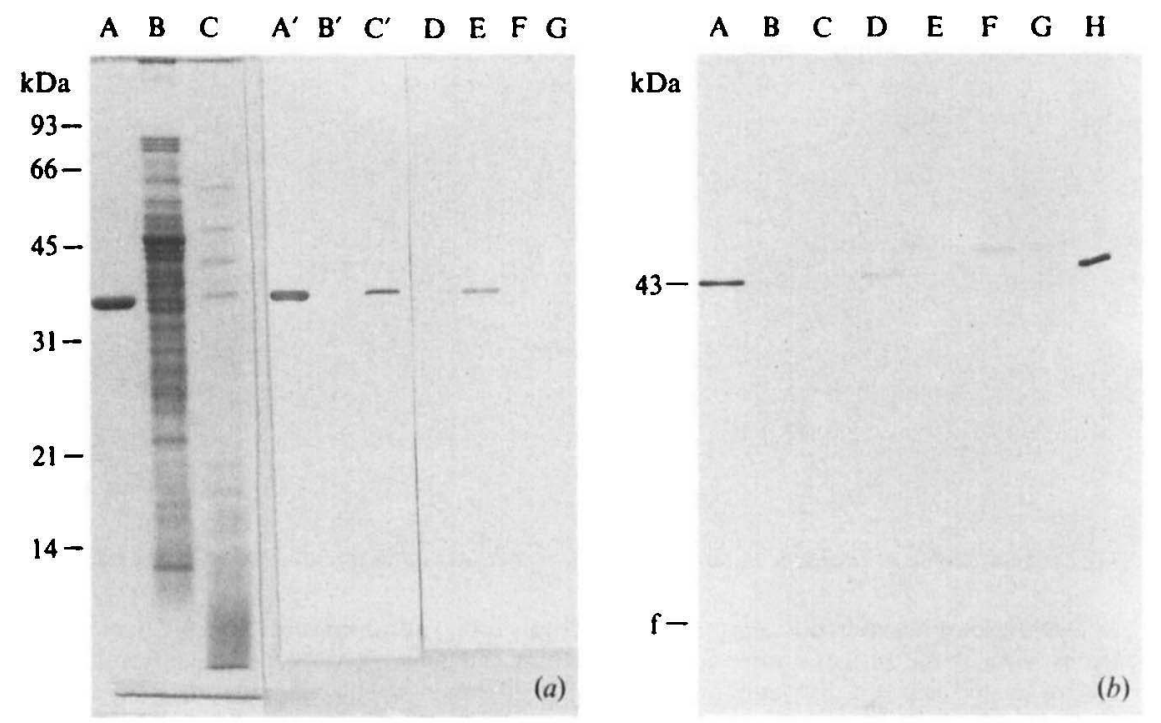

Fig. 3. Identification of fimbrilin bands by SDS-PAGE and Western blotting analysis. Fimbriae and whole cell lysate were applied to SDS-PAGE and gels were stained with Coomassie brilliant blue (lanes $A, B$, and $C$ in $a$ ) or were transferred to a nitrocellulose sheet (lanes $A^{\prime}$ to $G$ in $a$ and lanes $A$ to $H$ in $b$ ). The transferred sheet was immersed in BSA solution to block unoccupied protein-binding sites, and then incubated with rabbit anti-fimbrilin serum. Immuno-reactive bands were detected as described in the text. (a) Lanes $A, A^{\prime}$ and D, purified fimbriae, 4,1 and $0.1 \mu \mathrm{g}$ protein, respectively, applied to SDSPAGE; $B$ and $B^{\prime}, B$. macacae cell lysate, $50 \mu \mathrm{g}$ protein; $C$ and $C^{\prime}, B$. gingivalis 1112 cell lysate, $50 \mu \mathrm{g}$ protein; E, F, and G, B. gingivalis 381 and W83, and B. loescheii ATCC 15930, respectively, $25 \mu \mathrm{g}$ protein each. (b) Western blotting analysis of various $B$. gingivalis strains. Lanes $A$ and $\mathrm{H}, 381,20 \mu \mathrm{g}$ protein ; B, H184; C, 222; D, D96A-2; E, I-2; F, ESO-51 ; G, ESO-10, 40-50 $\mu$ g protein applied on SDSPAGE. $f$, Dye front in SDS-PAGE.

Identification of fimbrilin protein by Western blotting analysis. In preliminary experiments, the anti-fimbriae and anti-fimbrilin sera were used to detect oligomeric forms of fimbriae and fimbrilin (monomers) from strain 381, on Western blotting nitrocellulose sheets following SDSPAGE. The anti-fimbrilin serum, but not the anti-fimbriae serum, reacted with a protein with an apparent molecular mass of $43 \mathrm{kDa}$. The complete dissociation of fimbriae into fimbrilin monomers was necessary for detection with the anti-fimbrilin serum. This was expected from previous experiments (Yoshimura et al., 1984b, 1985) and was observed regardless of whether the fimbrial preparation was pure or crude. A typical result is shown in Fig. 3. The anti-fimbrilin serum reacted with a $43 \mathrm{kDa}$ protein band on the nitrocellulose sheet (Fig. $3 a$, lane D) when as little as $0.1 \mu \mathrm{g}$ of purified fimbriae was used for SDS-PAGE. Whole cell lysates (20-100 $\mu \mathrm{g}$ protein) were prepared by sonication and used for Western blotting analysis. An interesting finding was that some strains, from several laboratories, appeared to have an immuno-reactive protein with an apparent molecular mass of $46 \mathrm{kDa}$ (Fig. $3 \mathrm{~b}$, lanes $\mathrm{F}$ and G). Only the $46 \mathrm{kDa}$ and the $43 \mathrm{kDa}$ proteins were detected in this type of analysis, indicating that the antiserum was indeed specific to fimbrilin. The immuno-reactive $46 \mathrm{kDa}$ protein could reflect the presence either of a precursor of fimbrilin or of fimbrilin with a slightly slower migration rate. Trials to isolate and to purify fimbriae from strain 14018 are now in progress to clarify this. The isolated and purified $46 \mathrm{kDa}$ protein preparation which was reactive with anti-fimbrilin serum on an immunoblot was found to be filamentous by negative staining (Y. Suzuki, unpublished observation). The amino-terminal sequence (first 20 residues) of the $46 \mathrm{kDa}$ protein ( $\mathrm{F}$. Yoshimura, unpublished data) indicates that this protein has a similar primary structure to the fimbriae from strain 381 . The overall results showed a good correlation between Ouchterlony and immunoblotting tests, although the immunoblotting test resulted in four more positive results (Table 1). 
Species specificity of $B$. gingivalis fimbriae. B. gingivalis fimbriae were shown to be species specific when bacterial agglutination, Ouchterlony immunodiffusion and immunoblotting analyses were done with the following related Bacteroides species: B. asaccharolyticus ATCC 25260, B. melaninogenicus ATCC 25845, B. loescheii ATCC 15930, B. denticola ATCC 33185, B. intermedius ATCC 25611, B. levii, B-151, B. endodontalis ATCC 35406 and B. macacae ATCC 33141. None of the immunological tests for these species were positive.

Effect of haemin on fimbriation. McKee et al. (1986) showed that, in B. gingivalis W50 grown in a chemostat under conditions of haemin excess, cells had fewer extracellular vesicles and were more commonly coccus shaped and more heavily fimbriated than cells grown without haemin. The effects of haemin on four strains (EN-7, D67D-9, W83 and JKG-10) were examined by morphological and immunological methods. The addition of haemin $\left(0.5 \mu \mathrm{g} \mathrm{ml}^{-1}\right)$ to the medium did not have a detectable effect on fimbriation in these strains. GAM broth, used as a basal medium, may contain some haemin since it was good for the fimbriation of strain 381 .

\section{DISCUSSION}

Fimbriate strains were found at a high frequency in each of the groups of strains, isolated independently from different laboratories, that we studied. This suggests that in $B$. gingivalis strains, fimbriae are as widespread as are Escherichia coli type 1 fimbriae. The type 1 fimbriae, often referred to as common fimbriae, are found in most $E$. coli strains and have been estimated to be produced by $70 \%$ of wild-type strains (Duguid et al., 1979), when determined by a Dmannose inhibitable haemagglutination assay. The prevalence of fimbriae among $B$. gingivalis is supported by the findings of Yoshimura et al. (1987) that sera from $66 \%$ of patients with adult periodontal diseases had specific antibodies against $B$. gingivalis fimbriae.

In this study, most $B$. gingivalis fimbriae were shown to be immunologically related to those on $B$. gingivalis 381, a strain used worldwide. A total of 15 strains of $B$. gingivalis had fimbriae with a different fimbrilin protein that migrated slowly at a position corresponding to an apparent molecular mass of $46 \mathrm{kDa}$, with immuno-reactivity similar to that of 381 fimbriae. This is the first report on the molecular heterogeneity of $B$. gingivalis fimbriae.

The most favourable conditions of culture for fimbrial expression in $B$. gingivalis have not yet been established, although a recent report found that haemin may play a key role in fimbriation (McKee et al., 1986). The expression of $E$. coli type 1 fimbriae is suppressed by growth on solid media (Swaney et al., 1977). A similar situation has been observed in several B. gingivalis strains (Y.Suzuki, unpublished results). A rich complex medium (GAM medium), probably containing a certain amount of haemin, either as broth or as semi-solid medium for culture and for short storage, respectively, has been mainly used in the present study. Under these conditions, $B$. gingivalis 381 has expressed many fimbriae in a stable and constant manner for at least 4 years.

Of the three immunological methods used here, immunoblotting analysis was the most reliable and sensitive, although its procedures are not the simplest. An obvious reason is that immuno-reactive bands can be compared with those of purified fimbriae with respect to the migration rate in gel electrophoresis. Traditional methods such as bacterial agglutination and Ouchterlony immunodiffusion are convenient and simpler. However, the two methods tend to give false negative results for $B$. gingivalis fimbriae, probably due to the presence of only small numbers of fimbriae.

Strains W50 and W83, on which we could not detect fimbriae by immunological methods, have been found by McKee et al. (1986) and Handley \& Tipler (1986), to indeed be fimbriate, by negative staining. This indicates that electron microscopic studies are more sensitive in detecting surface structures, such as fimbriae, than the immunological methods applied here. Since detection is highly dependent upon technique, particularly for thin fimbriae such as those of $B$. gingivalis, some fimbriate strains, in which the proportion of fimbriate cells is very small, could mistakenly be considered to be non-fimbriate. In fact strains W50 and W83 seem to have a very few fimbriate cells (personal communication from Dr P. S. Handley). A very few detached 
fimbriae from a cell suspension of strain W83 were also observed in this study. This was supported by genetic studies indicating that W83 has a fimbrilin gene on its chromosome, although restriction fragment length polymorphism of DNA was revealed (F. Yoshimura, unpublished results and a personal communication from Dr D. P. Dickinson).

This work was supported by a grant-in-aid for scientific research from the Ministry of Education, Science and Culture of Japan.

This work would not have been possible without the generous help of colleagues from various institutes. We especially thank Drs W. J. Loesche, G. Sundqvist, S. Kunihiro, L. V. H. Moore, E. Newbrun, C. I. Hoover, J. J. Zambon, R. J. Genco, M. Nakamura, H. Suido, K. Okuda, S. Hamada and T. Koga for their interest and advice, and for sending bacterial strains. We also thank Mr K. Barrymore for helpful advice and discussion on the manuscript.

\section{REFERENCES}

Duguid, J. P., Clegg, S. \& Wilson, M. I. (1979). The fimbrial and nonfimbrial haemagglutinins of Escherichia coli. Journal of Medical Microbiology 12, 213227.

Handley, P. S. \& TiPLeR, L. S. (1986). An electron microscope survey of the surface structures and hydrophobicity of oral and non-oral species of the bacterial genus Bacteroides. Archives of Oral Biology 31, 325-335.

HolT, S. C. (1982). Pathogenic and virulence factors in periodontal disease. Bacterial surface structures and their role in periodontal disease. In Host-Parasite Interactions in Periodontal Disease, pp. 139-150. Edited by R. J. Genco \& S. E. Mergenhagen. Washington DC: American Society for Microbiology.

Lugtenberg, B., Meijers, J., Peters, R., Van Der HoEK, P. \& VAN ALPEN, L. (1975). Electrophoretic resolution of the 'major outer membrane protein' of Escherichia coli $\mathrm{K}-12$ into four bands. FEBS Letters 58, 254-259.

MCKee, A. S., McDermid, A. S., Baskerville, A., DowsetT, A. B., Ellwood, D. C. \& Marsh, P. D. (1986). Effect of hemin on the physiology and virulence of Bacteroides gingivalis W50. Infection and Immunity 52, 349-355.

OKUDA, K. \& TAKAZOE, I. (1974). Haemagglutinating activity of Bacteroides melaninogenicus. Archives of Oral Biology 19, 415-416.

Okuda, K., Slots, J. \& Genco, R. J. (1981). Bacteroides gingivalis, Bacteroides asaccharolyticus, and Bacteroides melaninogenicus subspecies: cell surface morphology and adherence to erythrocytes and human buccal epithelial cells. Current Microbiology 6, 7-12.

Slots, J. \& Genco, R. J. (1984). Black-pigmented Bacteroides species, Capnocytophaga species and Actinobacillus actinomycetemcomitans in human periodontal disease. Journal of Dental Research 63, 412421.

SLOTS, J. \& GibBons, R. J. (1978). Attachment of Bacteroides melaninogenicus subsp. asaccharolyticus to oral surfaces and its possible role in colonization of the mouth and of periodontal pockets. Infection and Immunity 19, 254-264.

SWaney, L. M., LiU, Y.-P., To, C.-M., To, C.-C., IPPEN-IHLER, K. \& BRINTON, C. C., JR (1977). Isolation and characterization of Escherichia coli phase variants and mutants deficient in type 1 pilus production. Journal of Bacteriology 130, 495-505.

TeW, J. G., Marshall, D. R., Moore, W. E. C., Best, A. M., Palcanis, K. G. \& RanNy, R. R. (1985). Serum antibody reactive with predominant organisms in the subgingival flora of young adults with generalized severe periodontitis. Infection and Immunity 48, 3C3-311.

Towbin, H., Staehelin, T. \& Gordon J. (1979). Elerctrophoretic transfer of proteins from polyacrylamide gels to nitrocellulose sheets: procedure and some applications. Proceedings of the National Academy of Sciences of the United States of America 76, 4350-4354.

Yoshimura, F., Nishikata, M., Suzuki, T., Hoover, C. I. \& NewBRUN, E. (1984a). Characterization of trypsin-like protease from the bacterium Bacteroides gingivalis isolated from human dental plaque. Archives of Oral Biology 29, 559-564.

Yoshimura, F., Takahashi, K., Nodasaka, Y. \& SUZUKI, T. (1984b). Purification and characterization of a novel type of fimbriae from the oral anaerobe Bacteroides gingivalis. Journal of Bacteriology 160, 949-957.

Yoshimura, F., Takasawa, T., Yoneyama, M., Yamaguchi, T., Shiokawa, H. \& Suzuki, T. (1985). Fimbriae from the oral anaerobe Bacteroides gingivalis : physical, chemical, and immunological properties. Journal of Bacteriology 163, 730-734.

Yoshimura, F., Sugano, T., Kawanami, M., Kato, H. \& SUZUKI, T. (1987). Detection of specific antibodies agains fimbriae and membrane proteins from the oral anaerobe Bacteroides gingivalis in patients with periodontal diseases. Microbiology and Immunology 31, 935-941. 